\title{
Portfólio reflexivo: uma estratégia para a formação em medicina
}

\author{
Reflective portfolio: a strategy for medical \\ education
}

\author{
Roseli Ferreira Silva ${ }^{\mathrm{I}}$ \\ Marcos Antonio Francisco ${ }^{\mathrm{I}}$
}

\section{PALAVRAS-CHAVE \\ - Portfólio \\ - Formação médica \\ - Ensino-aprendizagem \\ - Avaliação}

\begin{abstract}
R E S U M O
Esta investigação discute a estratégia do portfólio reflexivo na formação médica no contexto de um currículo inovador. O objetivo do estudo foi identificar a percepção dos estudantes quanto ao uso do portfólio reflexivo na Unidade Educacional de Prática Profissional. Caracteriza-se como um estudo de caso, no qual a análise dos dados foi realizada, na perspectiva qualitativa, por meio da técnica de análise de conteúdo; na perspectiva da análise quantitativa, foi utilizada medida de frequência simples. A coleta de dados foi feita mediante aplicação de um questionário com questões abertas. Os sujeitos do estudo foram 33 estudantes da segunda série. Os resultados apontam a contribuição do portfólio para a formação profissional, na medida em que permitiu ao estudante o acompanhamento e a organização do cuidado à saúde das pessoas sob sua responsabilidade e proporcionou um processo de autoavaliação. Por outro lado, a compreensão de portfólio apontada pelos estudantes se distancia em grande parte da concepção de portfólio reflexivo, pois pouca ou nenhuma contribuição para o desenvolvimento da capacidade reflexiva foi considerada pelos estudantes.
\end{abstract}

\begin{abstract}
A B S T R A C T
This study addresses the reflective portfolio (RP) strategy in medical education in the context of an innovative curriculum. The study aimed to identify students' perceptions concerning the use of RP in the Educational Unit on Professional Practice. This was a case study of qualitative data using the content analysis technique; the quantitative analysis was based on simple frequencies. Data were collected with a questionnaire using open-ended questions. The sample included 33 second-year medical students. The results indicated the portfolio's contribution to professional training, to the extent that it allowed students to monitor and organize the care of patients under their responsibility, while fostering a self-assessment process. Meanwhile, the students' understanding of the portfolio largely diverged from the reflective portfolio concept, in which the students identified little or no contribution to the development of reflective capacity.
\end{abstract}




\section{O CONTEXTO DA ELABORAÇÃO DO PORTFÓLIO}

Esta investigação se inscreve no contexto de um currículo inovador para a formação médica no curso de Medicina da Universidade Federal de São Carlos, no qual o plano curricular é integrado e interdisciplinar, inclui processos metodológicos e pedagógicos inovadores e é orientado pelo desenvolvimento da competência profissional esperada para o médico no contexto brasileiro.

Esta proposta de formação é de natureza crítico-reflexiva, sustentada numa perspectiva de construção do conhecimento a partir da problematização da realidade, ou seja, na articulação da teoria com a prática e na participação ativa do estudante no processo de aprendizagem. Cada série deste currículo é organizada por duas grandes Unidades Educacionais, a de Simulação da Prática Profissional e a de Prática Profissional1.

A Unidade Educacional de Prática Profissional (UEPP) é construída a partir da vivência dos estudantes em contextos reais da prática médica. Para as duas primeiras séries, o cenário privilegiado do processo de ensino-aprendizagem são as Unidades de Saúde da Família (USF) do município.

Neste cenário, dois dias por semana, os estudantes, em grupos de oito, junto com a equipe de saúde e sob supervisão do preceptor - médico da USF -, se responsabilizam pelo cuidado à saúde de um grupo de pessoas. O cuidado realizado pelos estudantes ocorre de acordo com o grau de autonomia destes, esperado para a série em que o aluno se encontra.

Num terceiro período semanal, cada grupo realiza encontros de reflexão sobre as práticas desenvolvidas, com a participação de um professor, que exerce o papel de facilitador da aprendizagem, e do preceptor no papel de cofacilitador. Estes encontros constituem ciclos de aprendizagem.

Na primeira etapa do ciclo de aprendizagem, denominada síntese provisória, a partir de um "disparador", como as histórias clínicas realizadas pelos estudantes em visitas domiciliares, ocorrem discussões considerando as capacidades prévias dos estudantes - nas dimensões cognitiva, psicológica e atitudinal-, as quais permitem identificar lacunas no conhecimento e levantar questões de aprendizagem.

Na segunda etapa do ciclo de aprendizagem, a partir dessas questões de aprendizagem, num processo individual, cada estudante se responsabiliza pela identificação de fontes e busca de informações que permitam a análise e elaboração de uma síntese individual coerente com as questões de aprendizagem.

Numa terceira etapa, num novo encontro do grupo, os estudantes discutem os achados e elaboram uma nova síntese com aprofundamentos conceptuais, científicos e metodológicos a partir das pesquisas individuais e estruturação das questões de aprendizagem. Desta forma, novos ciclos vão se constituindo sucessivamente a partir das situações reais vividas na prática profissional.

Nesta perspectiva, várias estratégias pedagógicas e metodológicas foram necessárias ao desenvolvimento curricular em contexto real, e uma delas foi a adoção do portfólio reflexivo.

Assim, em geral, o portfólio dos estudantes é organizado a partir desses ciclos de aprendizagem e a partir da realização das atividades da prática, tal como o cuidado prestado aos indivíduos. Assim, pode ser organizado por família, contendo a história de vida da família, história clínica, exame clínico, levantamento de necessidades de saúde e do plano de cuidados do paciente, entre outros.

Nesta Unidade, o portfólio é utilizado como uma estratégia que potencializa a reflexão sobre as práticas desenvolvidas pelos estudantes, apoiando o processo de construção de conhecimento contextualizado e o desenvolvimento pessoal e profissional dos envolvidos, favorecendo a compreensão dos significados possíveis e a atribuição de sentido(s) às situações e aos conceitos que constituem o cerne da aprendizagem, estimulando o desenvolvimento crítico e reflexivo do formando.

Todo o processo de construção do conhecimento é sempre mediado e enriquecido pelos professores e preceptores, seja no contato individual com o estudante, no acompanhamento de suas práticas, nos pequenos grupos de reflexão ou na construção do portfólio reflexivo.

\section{A ESTRATÉGIA PORTFÓLIO REFLEXIVO}

O portfólio tem sido utilizado em diferentes áreas de formação profissional, cumprindo um papel importante em vários contextos educativos como estratégia que potencializa a construção do conhecimento de forma reflexiva, com vista a uma progressiva emancipação dos sujeitos em formação. Na formação em saúde, o portfólio tem sido utilizado principalmente em currículos inovadores.

Na educação médica, o portfólio aparece em diferentes âmbitos da formação, ou seja, na graduação, no internato e nos programas de residência. Nestes, o portfólio tem sido empregado como instrumento de registro, memória, planejamento, autoavaliação, avaliação e principalmente para o desenvolvimento da capacidade reflexiva. Ainda quando utilizado em atividades de prática, em contextos reais, o portfólio permite ao estudante refletir sobre aspectos de comunicação e os relacionados aos domínios afetivo e emocional ${ }^{2}$. 
Para Vilas Boas ${ }^{3}$, o portfólio tem sido considerado um dos saberes a serem incorporados pelo estudante, pois permite que este seja o sujeito construtor de seu saber e prática, numa dimensão que ultrapassa a reprodução das teorias no mundo real. O portfólio possibilita ao estudante ser agente interventor sobre sua realidade, produzindo saberes e avaliando suas limitações, o que permite a busca de novos conhecimentos e a transformação da prática.

Nesta mesma direção, Sá-Chaves (p. 15) ${ }^{4}$ salienta que:

esta estratégia permite ao estudante uma ampliação e diversificação do seu olhar, estimulando a tomada de decisões, a necessidade de fazer opções, de julgar, de definir critérios, de se deixar invadir por dúvidas e por conflitos, para deles poder emergir mais consciente, mais informado, mais seguro de si e mais tolerante quanto às hipóteses dos outros.

Desta forma nasce o portfólio reflexivo.

Sá-Chaves ${ }^{4}$ aponta algumas contribuições do portfólio reflexivo quando este é desenvolvido pelo estudante durante certo tempo sob a supervisão de um professor: ele promove o desenvolvimento reflexivo nos níveis cognitivo e metacognitivo; estimula o processo de enriquecimento conceitual; promove a fundamentação dos processos de reflexão para, na e sobre a ação; garante mecanismos de aprofundamento conceitual por meio de feedback entre os sujeitos da aprendizagem; estimula a originalidade e a criatividade individual; contribui para a construção personalizada do conhecimento para, em e sobre a ação; permite a regulação, em tempo útil, de conflitos; facilita os processos de auto e heteroavaliação.

Também para Driessen et al. ${ }^{2}$, a introdução do portfólio desde o início da formação médica é o caminho para uma aprendizagem reflexiva. Isto porque, por meio dele, o estudante pode olhar para as suas ações de forma sistemática e analisá-las com cuidado, tomando conta da construção de seu próprio processo de conhecimento teórico e de métodos alternativos de ação. Ou seja, refletir sobre o contexto em que se vive e ter um aprendizado por meio de vivências e observação da realidade tornam a aprendizagem mais significativa e não meramente um acúmulo de conhecimentos ${ }^{5}$.

Desta forma, na perspectiva da avaliação, o portfólio tem sido utilizado para avaliar o processo de aprendizagem do estudante, rompendo com a lógica certificativa e de memorização de conteúdos, cujo objetivo é quantificar o saber do aluno.

Outra questão suscitada sobre o portfólio, de acordo com Vilas Boas ${ }^{3}$, é o reconhecimento deste como eixo organizador do trabalho pedagógico, em virtude da importância que o portfólio passa a ter durante todo o processo de aprendizagem. Para tan- to, segundo Driessen et al. ${ }^{2}$, o portfólio deve ter uma estrutura apropriada previamente definida; um método de avaliação adequado; suficiente número e relevantes experiências para reflexão; e suficiente capacidade dos professores para acompanhá-lo e avaliá-lo.

Segundo Hernández ${ }^{6}$, a construção do portfólio pode seguir alguns passos, tais como: o estabelecimento do objetivo do portfólio por parte do docente; o estabelecimento das finalidades de aprendizagem por parte de cada estudante; a integração das evidências e experiências de aprendizagem; a seleção das fontes que comporão o portfólio; e a reflexão do estudante acerca de seu próprio desenvolvimento.

Para que o portfólio propicie de fato os processos reflexivos, e não apenas ocupe o lugar de um instrumento ou recurso de informação para avaliação, solicita-se aos estudantes a elaboração de discursos narrativos, de natureza crítico-reflexiva, acerca das vivências destes nas atividades de prática, nos processos de formação ${ }^{7}$.

Desta forma, segundo Sá-Chaves (p. 15) ${ }^{8}$, em ciclos sucessivos e interativos de reflexão proativa, o portfólio pode fornecer

evidências não apenas sobre os descritores das ações vividas e refletidas, sobre os seus constrangimentos e coerência, sobre o seu grau de sucesso ou insucesso face ao esperado, mas, sobretudo, permite fazer a captura do fluir do pensamento do mesmo formando à medida que vai - ou não - sendo capaz de analisar criticamente as suas práticas desde o nível técnico, ao nível ético e de nesse exercício se autoavaliar como sujeito responsável na transformação das situações e no sentido dos valores que fundamentam e dignificam a condição humana.

De acordo com Rees e Sheard ${ }^{9}$, na visão dos estudantes, o desenvolvimento da capacidade reflexiva é considerado importante, bem como a avaliação do portfólio é oportuna e vantajosa para eles. Entretanto, apontam que o conceito de reflexão é de difícil compreensão, que fazê-la é muito trabalhoso e que somente será realizada pelos estudantes se for uma atividade compulsória.

Nesta mesma direção, Driessen et al.$^{10}$ alertam que o portfólio é um valioso instrumento de avaliação e de desenvolvimento da habilidade reflexiva, porém o método é vulnerável em condições adversas e pode facilmente desapontar (estudantes e professores). Assim, sugerem que aqueles que têm intenção de implementar o portfólio devem considerar cuidadosamente a disponibilidade para criar um ambiente favorável de aprendizagem, necessário ao sucesso do uso do portfólio. 


\section{A INVESTIGAÇÃO DA ESTRATÉGIA PORTFÓLIO REFLEXIVO}

Considerando a importância da estratégia portfólio reflexivo para estudantes e professores no curso de Medicina da UFSCar, foi realizada uma investigação com o propósito de evidenciar tal estratégia como contributo para a formação médica, na perspectiva da profissionalização reflexiva. Esta investigação também passa a ser um instrumento de comunicação e divulgação acerca das potencialidades do portfólio para a formação de profissionais da saúde.

Pela natureza do objeto de estudo, esta investigação utilizou uma metodologia caracterizada como estudo de caso, de análise qualitativa e quantitativa. Seu objetivo foi identificar a percepção dos estudantes quanto ao uso do portfólio reflexivo na Unidade Educacional de Prática Profissional na segunda série do curso de Medicina da UFSCar em 2007. Os sujeitos do estudo foram 33 estudantes da segunda série de 2007 entre os 37 matriculados (quatro estudantes não responderam o questionário). A escolha desta série para a investigação se deu pelo fato de o curso médico em 2007 estar no segundo ano de implantação.

A coleta de dados foi realizada mediante aplicação de um questionário, com questões abertas. A elaboração do questionário foi fundamentada na exploração de questões definidas pelos pesquisadores, por meio dos enquadramentos teóricos que fundamentam o estudo. Foi realizado um pré-teste com quatro estudantes de Medicina de outra faculdade no Estado de São Paulo que utiliza o portfólio reflexivo. Este pré-teste possibilitou adequações nas questões que compuseram o questionário. Na realização da pesquisa foram seguidos todos os procedimentos de autorização institucional e parecer do Comitê de Ética e Pesquisa em Seres Humanos da UFSCar. Foi observada a resolução ${ }^{0}$ 196/1996 do Conselho Nacional de Saúde sobre pesquisa envolvendo seres humanos no que se refere ao termo de responsabilidade do pesquisador e de consentimento livre e esclarecido dos sujeitos que manifestarem anuência à participação na pesquisa. A análise dos dados foi realizada, na perspectiva qualitativa, com uso da técnica de análise de conteúdo proposta por Bardin ${ }^{11}$; na perspectiva da análise quantitativa foram utilizadas medidas de frequência simples.

\section{ANÁLISE DOS DADOS ACERCA DO USO DO PORTFÓLIO REFLEXIVO}

Pela similaridade e complementaridade das respostas, a análise será apresentada articulando as duas primeiras questões do questionário: “O que é o portfólio para você?" e “Na sua opinião, qual a contribuição do portfólio para a aprendizagem do estu- dante na Unidade de Prática Profissional?" E separadamente: "Como é o processo de construção do seu portfólio na Unidade de Prática Profissional?" "Como é a participação do professor e preceptor no seu portfólio?" Para cada uma das questões foram identificadas unidades de registro que se agruparam e permitiram a construção das categorias empíricas desta análise.

\section{A compreensão e a contribuição do portfólio}

A partir da questão "O queéo portfólio para você?", foi possível identificar três categorias da compreensão dos sujeitos a respeito do que seja portfólio para eles na UEPP: 39,39\% se referiram ao portfólio como objeto; para 39,39\%, o portfólio é uma fonte de informação; para $21,21 \%$, é uma ferramenta de avaliação (Tabela 1).

Apesar de uma parcela significativa dos estudantes compreender o portfólio numa dimensão bastante instrumental (como objeto), ao serem perguntados sobre a contribuição do portfólio para a aprendizagem na UEPP, os estudantes apresentaram ideias positivas e significativas desta contribuição para o seu processo de formação. Assim, 45,45\% relataram que o portfólio ajudou no acompanhamento das famílias; 39,39\% reforçaram que o portfólio ajuda na organização das informações sobre as famílias e de seus estudos; e 15,15\% voltaram a reconhecer o portfólio como instrumento de avaliação, aqui mais especificamente de autoavaliação (Tabela 2). A seguir será apresentada a análise de cada uma destas categorias.

Dos 39,39\% dos estudantes que se referiram ao portfólio como objeto, 30,76\% o denominaram como arquivo; $46,15 \%$ como fichário; 7,69\% como pasta; e 15,38\% não denominaram. Desta forma, o portfólio foi visto como o lugar onde se guarda e armazena "tudo" o que acontece na UEPP, que passa a ser um arquivo do conjunto de documentos ou de dados escritos sobre as atividades da Unidade. Pouca ou nenhuma importância ou utilidade foi atribuída ao portfólio nesta categoria para além do "lugar". Esta representação de portfólio se assemelha à ideia do uso do portfólio como um diário de campo, lugar onde apenas se registram as tarefas e atividades realizadas. Desta forma, o portfólio não foi reconhecido pelos sujeitos como ferramenta que contribuiu para a aprendizagem. A frase a seguir representa esta ideia:

O portfólio é o local onde eu arquivo minhas visitas. Na prática profissional armazeno uma espécie de prontuário dos meus pacientes e as sínteses dos estudos dos casos dos pacientes. (E27) 
Tabela 1

Distribuição das categorias empíricas segundo freqüência absoluta e percentual

\begin{tabular}{lcc}
\hline & \multicolumn{2}{c}{ Frequência } \\
\cline { 2 - 3 } Categoria & Número de ocorrências & Porcentagem \\
\hline Portfólio como objeto & 13 & 39,39 \\
Portfólio como fonte de informação & 13 & 39,39 \\
Portfólio como ferramenta de avaliação & 7 & 21,21 \\
\hline Total & 33 & 100,00 \\
\hline
\end{tabular}

Tabela 2

Distribuição da representação dos sujeitos da pesquisa acerca da contribuição do portfólio para a aprendizagem

\begin{tabular}{lcc}
\hline & \multicolumn{2}{c}{ Frequência } \\
\cline { 2 - 3 } Contribuição do portfólio & Número de ocorrências & Porcentagem \\
\hline Acompanhamento das famílias & 15 & 45,45 \\
Organização das informações & 13 & 39,39 \\
Instrumento de autoavaliação & 5 & 15,15 \\
Total & 33 & 100,00 \\
\hline
\end{tabular}

Dos $39,39 \%$ dos estudantes que se referiram ao portfólio como fonte de informação, $23,07 \%$ o apontaram como o lugar de acesso à informação; $15,38 \%$ como local onde se organizam o conhecimento e a informação; $61,53 \%$ como local de registro que permite acompanhar a evolução da aprendizagem. Apesar de as três ideias parecerem muito próximas, há uma progressão quanto ao uso do portfólio. Este foi referido como o lugar onde se arquivam todos os documentos das atividades da UEPP, de forma organizada, segundo seu uso e sua natureza, de maneira a facilitar a busca de informações quando necessário. Desta forma, o portfólio passa a ser uma fonte de informação contínua para os estudantes em diferentes situações.

Portfólio é o local onde estão armazenadas minhas sínteses e reflexões. Mais do que um fichário que guarda resumos, o portfólio garante meu acesso a informações, raciocínios, abordagem e como eu penso no cuidado do paciente de forma individual e coletiva. (E31)

Nesta categoria, a contribuição do portfólio para os estudantes foi somente na dimensão organizadora de informaç̃os di- versas com praticidade, que foram importantes para a aprendizagem. O portfólio estimulou a organização dos estudos realizados. Com isso, o estudante pode ter fácil acesso a estes, que passam a ser um instrumento de trabalho do dia a dia. Desta forma, para estes estudantes, pouca ou nenhuma contribuição foi dada ao portfólio numa dimensão reflexiva da aprendizagem.

Sua contribuição seria pelo estímulo dado a uma maior organização dos estudos realizados e maior facilidade na retomada destes. (E17)

Dos $21,21 \%$ de estudantes que apontaram o portfólio como ferramenta de avaliação, 57,14\% se referiram à avaliação do desenvolvimento da aprendizagem do estudante e do curso; $28,57 \%$ se referiram ao portfólio como ferramenta que também possibilitou avaliar o cuidado prestado pelos estudantes às famílias e aos pacientes acompanhados; e 14,28\% não especificaram o foco da avaliação.

Segundo os estudantes, o portfólio permitiu uma reflexão sobre o seu próprio processo de aprendizagem e a própria prática, ou seja, sobre o cuidado à saúde das famílias e das pessoas sob sua responsabilidade. Este processo também possibilitou 
identificar fortalezas e fragilidades, reconhecer as lacunas de conhecimento e planejar ações para superá-las, levando ao aperfeiçoamento do estudante e, consequentemente, à melhora do plano de cuidados. O portfólio, além de ser considerado um instrumento que permitiu a autoavaliação do processo de aprendizagem, também possibilitou avaliar o cuidado à saúde prestado às pessoas e às suas famílias.

É um instrumento que tem como um dos objetivos refletir a atuação do estudante na sua realidade de prática. Logo, está como o estudante, em constante transformação e alteração no modo como o estudante enxerga os seus objetivos, a sua capacidade cognitiva, nas interpretações crítico-reflexivas e também a sua indução no olhar atento ao paciente. (E15)

A contribuição do portfólio como instrumento que permitiu o acompanhamento das famílias significou ter acesso ao conjunto de informações sobre a pessoa cuidada, já que o portfólio registra cronologicamente as histórias, os planos de cuidados e a evolução do cuidado. Neste sentido, permitiu acompanhar o processo saúde-doença, a evolução e a avaliação dos planos cuidados. Assim, este conjunto de ações pode se tornar importante para o processo de gestão do cuidado, visto que os estudantes acompanharão estas pessoas e suas famílias ao longo de toda a sua formação.

O portfólio contribuiu para a construção e o acompanhamento feito com os pacientes e famílias e para avaliação dos fatores positivos, negativos e levantamento das coisas que ainda devem ser feitas. (E7)

Outra contribuição do portfólio relatada pelos estudantes foi tê-lo como instrumento de autoavaliação, pois os estudantes registram as avaliações formativas realizadas na UEPP ao longo do curso. Esse registro permitiu aos estudantes perceber sua evolução e planejar ações para melhorar seu aprendizado. Alguns estudantes referiram que o portfólio possibilitou uma reflexão acerca da própria prática e uma análise crítica dos processos de aprendizagem, aparecendo aqui o princípio reflexivo da formação.

Com ele (portfólio) eu posso analisar melhor minha evolução, através de dados concretos e precisos de minha atuação na unidade de prática profissional com os dados, passo planejar melhor meu estudo. (E14) nuado e personalizado, garante o refazer das aprendizagens e potencializa sua qualidade. $\mathrm{O}$ estudante, de um modo inacabado, vai percebendo não só os conteúdos presentes neste processo de aprendizagem, como também os significados e sentidos que ele atribui à informação com a qual interage. Outro princípio contido nesta categoria é o da autoimplicação do estudante em sua aprendizagem.

\section{O processo de construção do portfólio}

A partir da questão "Como é o processo de construção do portfólio?" somente 36,36\% dos estudantes apontaram a qualidade do processo, e os outros 63,63\% não mencionaram esta qualidade. Para aqueles que fizeram referência à qualidade do processo, esta foi definida como não formal, um tanto tumultuada por problemas de organização da própria atividade da prática profissional, tanto do ponto de vista acadêmico como da organização da USF. Este processo foi referenciado pelos estudantes como um ato mecânico de arquivamento e desorganizado, pela falta de motivação em sua construção. Alguns estudantes relataram dificuldade de estabelecer uma organização; outros referiram que esse processo de construção evoluiu com o tempo, ajudado por todos os envolvidos no processo de aprendizagem, inclusive pelo professor.

Mesmo com todas as dificuldades apontadas, os estudantes relataram que o portfólio foi construído num processo, de forma contínua e diária. Este processo foi concomitante à construção do conhecimento seguindo o ciclo de aprendizagem dos pequenos grupos de reflexão da prática e em cada momento de trabalho junto às famílias e às atividades na USF. Neste processo de construção, foi possível identificar como o portfólio foi constituído, ou seja, as partes que compõem o portfólio na UEPP: 48,48\% dos estudantes por ciclo de aprendizagem e cuidado às pessoas; $39,39 \%$ não têm critérios predefinidos; $12,12 \%$ dos estudantes não fizeram referência à forma de construção do portfólio (Tabela 3).

Para 48,48\% dos estudantes o portfólio foi construído em duas partes. A primeira se refere ao trabalho no pequeno grupo de aprendizagem, em que incluem as narrativas da prática, as sínteses elaboradas a partir das questões de aprendizagem e as avaliações do processo. A outra parte se refere ao trabalho com as famílias e pessoas cuidadas por eles, incluindo histórias clínicas, registro das visitas domiciliares, planos de cuidados e outros.

Por meio destas duas categorias podemos inferir que o portfólio é uma estratégia na qual a avaliação, como processo conti- 
Tabela 3

Distribuição da representação dos sujeitos acerca das partes que compõem o portfólio

\begin{tabular}{lcc}
\hline Partes do portfólio & Frequência & Pómero de ocorrências \\
\cline { 2 - 3 } Ciclo de aprendizagem e cuidado às pessoas & 16 & 48,48 \\
Sem critérios definidos de organização & 13 & 39,39 \\
Não mencionou & 4 & 12,12 \\
Total & 33 & 100,00
\end{tabular}

O processo se dá só no momento de construção de aprendizado, nas reuniões de discussão de narrativas e histórias de família. (E20).

Dos estudantes que constroem o portfólio sem critérios predefinidos, 39,39\%, referem que apenas vão arquivando partes e registro das atividades desenvolvidas por eles. Podemos compreender em parte, a partir desta forma de construção do portfólio, as razões pelas quais os estudantes se referem ao portfólio como um instrumento mecânico de arquivo e não como um instrumento que permite a construção do conhecimento de forma reflexiva, com vistas aos processos de conscientização das conquistas e das lacunas de conhecimento.

\section{A Participação do Facilitador no Portfólio}

Quando solicitado aos estudantes que relatassem como foi a participação do professor - facilitador e/ou preceptor - na construção de seu portfólio, $60,60 \%$ deles relataram que houve participação dos professores, 33,33\% que não houve nenhuma participação, e 6,06\% não responderam (Tabela 4).

A participação do professor no portfólio foi referida como uma contribuição que levou o estudante a melhorar a organização do portfólio, no sentido de ampliar o potencial deste para a aprendizagem. Ainda afirmaram que o portfólio possibilitou ao professor verificar a evolução do estudante ao longo da UEPP. Outros relataram que houve uma contribuição do professor quando este analisava as histórias clínicas e os planos de cuidados realizados pelos estudantes das pessoas acompanhadas, ajudando-os na reflexão sobre o cuidado prestado. Desta forma, o portfólio se apresenta como uma estratégia de formação continuada e de verdadeiro suporte profissional e pessoal, potencializando a qualidade da intervenção realizada pelos estudantes na prática.

O professor me deu orientações muito boas a respeito de uma melhor organização e sistematização do port- fólio, o que me ajudou a otimizar o trabalho na prática. (E29)

Apenas como avaliador de determinadas anotações e condutas, questionando-as e estimulando a fundamentação das mesmas. (E22)

O portfólio conta uma história de aprendizagem pessoal e sempre única, que pode ser lida, relida, avaliada e autoavaliada por ambos, professor e estudante. E assim o professor, em tempo útil, ao tomar conhecimento do "momento" do estudante, poderia contribuir com orientações e informações apropriadas, um feedback oportuno que reencaminhasse os processos de desenvolvimento do estudante. Esta ausência de 33,33\% dos professores no acompanhamento do portfólio do estudante nos revela que tais professores não têm considerado o portfólio como um instrumento que contribui para evidenciar a aprendizagem dos estudantes, sobretudo do que ainda falta, do que ainda se mantém em aberto em termos de aprendizagem.

\section{CONSIDERAÇÕES FINAIS}

Embora os dados desta investigação apontem que a maioria dos estudantes compreende o portfólio como um objeto ou fonte de informação e que apenas uma pequena parcela o visualiza como ferramenta de aprendizagem, quase a totalidade reconhece a contribuição do portfólio como estratégia educacional para a sua formação profissional. O reconhecimento desta contribuição se deu na medida em que o portfólio permitiu aos estudantes o acompanhamento e a organização do cuidado à saúde das pessoas sob sua responsabilidade e proporcionou um processo de autoavaliação quando os estudantes o utilizaram para analisar sua evolução no processo de cuidado à saúde. 
Tabela 4

Distribuição da representação dos sujeitos acerca da participação do professor na construção do portfólio

\begin{tabular}{lcc}
\hline & & Frequência \\
Participação do professor no portfólio & Número de ocorrências & Porcentagem \\
\cline { 2 - 3 } Professor participou & 20 & 60,60 \\
Professor não participou & 11 & 33,33 \\
Não respondeu & 2 & 6,06 \\
Total & 33 & 100,00
\end{tabular}

Os dados deste estudo mostraram que a compreensão de portfólio apontada pelos estudantes se distancia em grande medida da concepção de portfólio reflexivo, pois pouca ou nenhuma contribuição para o desenvolvimento da capacidade reflexiva foi considerada pelos estudantes.

As razões para o sucesso do uso do portfólio como estratégia de desenvolvimento da habilidade reflexiva, sugeridas na literatura, repousam no suporte efetivo do professor, num sistema de orientação e avaliação formativa a partir do portfólio; numa clara proposta de estruturação do portfólio; e na introdução do portfólio logo no início da formação.

De acordo com os achados desta investigação, podemos sugerir que houve fragilidade em dois dos pontos acima citados: na participação do professor, principalmente no que se refere ao desenvolvimento da capacidade reflexiva, atuando o professor somente na orientação dos planos de cuidado desenvolvidos pelos estudantes; e na falta de orientação sobre a proposta do portfólio na UEPP logo no início do curso.

Este trabalho também procurou oferecer contribuições metodológicas para a formação de profissionais de saúde que envolva processos reflexivos em contextos reais da prática profissional.

\section{REFERÊNCIAS}

1. Curso de Medicina. Caderno do curso de medicina. São Carlos: Universidade Federal de São Carlos; 2007.

2. Driessen E, Van Tartwik J, Vermuntjd JD, Van der Vleuten CP. Use of portfolios in early undergraduate medical training. Med Teacher. 2003 Jan; 25(1):18-23.
3. Vilas Boas BMF. O portfólio no curso de pedagogia: ampliando o diálogo entre professor e aluno. Educ. Soc. 2005 Jan-Abrl; 26(90):291-306.

4. Sá-Chaves I. Portfólios reflexivos: estratégia de formação e de supervisão. Aveiro: Universidade de Aveiro; 2000. (Cadernos didácticos. Série Sup.; 1). 57p.

5. Rangel JNM, Nunes LC, Garfinkel M. O portfólio no ensino superior: práticas avaliativas em diferentes ambientes de aprendizagem. Pro-Posições. 2006;17(3):167-180p.

6. Hernández F. Cultura visual. mudança educativa e projeto de trabalho. Porto Alegre: Artmed; 2000. 262p.

7. Silva RF, Sá-Chaves I. Formação reflexiva: representações dos professores acerca do uso de portfólio reflexivo na formação de médicos e enfermeiros. Interface Comun Saúde Educ. 2008 Dez; 12(27): 721-734.

8. Sá-Chaves I. Formação, Conhecimento e Supervisão: contributos nas áreas da formação de professores e de outros profissionais. Aveiro: Universidade de Aveiro; 2000. (Estudos temáticos 1). 198p.

9 Ress C, Sheard C. Undergraduate medical students' views about a reflective portfolio assessment of their communication skills learning. Med Educ. 2004;38(2):125-8.

10. Driessen E, Van Tartwik J, Overeem K, Vermuntjd JD, Van der Vleuten CP. Conditions for sucessful reflective use of portfolios in undergraduate medical education. Med Educ. 2005; 39 (12):1230-5.

11. Bardin L. Análise de conteúdo. Lisboa: Edições 70; 1977. $226 \mathrm{p}$. 


\section{CONTRIBUIÇÃO DOS AUTORES}

Roseli F. da Silva, autora responsável, e Marcos Antônio Francisco, co-autor, contribuíram na coleta, análise interpretação dos dados assim como da redação do texto.

\section{CONFLITO DE INTERESSES}

Declarou não haver.

\section{ENDEREÇO PARA CORRESPONDÊNCIA}

Rua Vitor Manoel de Souza Lima, 410 - apto 31

São Carlos

CEP.13561-020 SP

E-mail:roselifs@ufscar.br 